\title{
Absence of effect of post-discharge socioeconomic circumstances on the outcome of dysvascular lower limb amputees: a prospective cohort study
}

\author{
PB Mathebula, VOL Karusseit, T Mokoena \\ Department of Surgery, School of Medicine, Faculty of Health Science, University of Pretoria, Pretoria, South Africa
}

Corresponding author: Prof VOL Karusseit (otto.karusseit@up.ac.za)

\begin{abstract}
Background: Significant mortality and morbidity occur after major lower limb amputation for diabetes-related foot complications and peripheral arterial disease. Risk factors for atherosclerosis and medical comorbidities are common in amputation for diabetes-related foot complications and are major determinants of outcome. Conversely, the effect of posthospitalisation circumstances on outcome has not been systematically studied. We hypothesised that poor socioeconomic circumstances after discharge would have an adverse effect on the outcome of major amputation in a developing country.

Objectives: To determine the association of the status of post discharge socioeconomic circumstances on the outcome of dysvascular amputation.

Methods: This was a prospective cohort study. Patients scheduled for major dysvascular lower limb amputation were recruited. Data were collected regarding the socioeconomic circumstances to which patients would be discharged, such as housing, income and personal care. Patients were followed up at our hospital, at clinics and later telephonically for three years. Mortality and wound morbidity were documented. Association of differences in status of socioeconomic factors and outcomes was analysed statistically.

Results: Ninety nine patients were enrolled. Eight patients died in hospital and 91 were discharged. The socioeconomic circumstances of discharged patients were relatively favourable, the majority living in brick houses (92\%) with running water $(87 \%)$. Most patients had a regular income $(86 \%)$, more than half had state/government grants. The availability of co-habitants, care givers and accessible medical facilities was also favourable. None of the different socioeconomic status levels demonstrated an effect on morbidity or mortality, all associations having a p-value greater than 0.05 (Chi-squared Fisher's exact and Spearman's rank correlation tests).

Conclusion: No association between socioeconomic status factors and post-discharge outcome of amputees was demonstrated. This is probably because the dysvascular amputees in this study cohort were living in relatively favourable circumstances.
\end{abstract}

S Afr J Surg 2018;56(4) http://dx.doi.org/10.17159/2078-5151/2018/v56n4a2588

\section{Introduction}

Major lower limb amputation is a greatly disruptive event in the life of a patient. Lifestyle is adversely affected, and great demands are placed on family and support systems. Dysvascular amputations are performed mainly in patients with diabetes mellitus and peripheral arterial disease. These patients are usually older and often afflicted by significant comorbidities. Mortality is therefore higher than in amputees for trauma or malignant neoplasia. ${ }^{1,2}$ Much has been written about the effect of comorbid conditions and peri-operative events on outcomes in dysvascular amputees, ${ }^{3,4,5,6}$ but very little on the effect of socioeconomic circumstances after discharge. The facility to which a patients is discharged has a major impact on mortality and rehabilitation. ${ }^{7,8}$ Discharge of patients in the developed world is usually to dedicated step-down rehabilitation units, skilled nursing facilities or supported homecare. ${ }^{7,8}$ Dedicated or skilled facilities are generally not available in the developing world and patients are often left to fend for themselves at home. It would be expected that adverse living and economic circumstances would have a negative effect on patient outcomes such as wound-related complications, mobility and survival after major lower limb amputation, as has been reported in other diseases. ${ }^{10}$ It would therefore be of interest to study the circumstances to which amputees in a developing world environment are discharged. We hypothesised that outcomes would be negatively affected by the status of the patients' post-discharge socioeconomic 
circumstances, anticipating that most patients would belong to the low income group with poor social support structures.

\section{Aim}

The aim of this study was to determine the socioeconomic circumstances to which major dysvascular amputees are discharged from our hospital and to analyse the possible effect of these circumstances on surgical wound outcome, rehabilitation and survival.

\section{Methods}

This was a prospective cohort study of patients undergoing major lower limb amputation secondary to peripheral arterial disease (PAD) and/or diabetes mellitus-related foot complications. Consecutive adult patients who were subjected to trans-tibial or trans-femoral amputation for non-salvageable vascular disease or otherwise unmanageable diabetic foot sepsis were approached to give consent for the study. This included patients undergoing formalization of the below knee or above knee amputation after initial supra-malleolar guillotine amputation had been performed to control spreading foot sepsis. Patients who consented to participate had the following information recorded: demographics, clinical details (including the underlying pathology), comorbidities, smoking history, and the body mass index (BMI).

A questionnaire was administered to patients while in the hospital regarding home and personal circumstances. This included details regarding housing conditions, income, employment, caregivers and available medical facilities.

Patients received in-hospital physiotherapy post-surgery. Surgical complications and peri-operative deaths were recorded. Patients were discharged home, to be followed up at the surgery outpatient clinic in our hospital and later at their local facilities. The patients were followed up physically for at least 30 days after discharge from hospital, and follow-up was continued telephonically for 3 years. If a patient did not report for follow-up, telephonic contact was made with the patient or the family. The prevailing condition of the patient was ascertained as well as the reason for not reporting for follow-up. If the patient or family were not traceable, the population register was examined to determine if and when the patient died.

Patients for whom it was considered to be appropriate were referred for consideration for fitting of a prosthesis once the amputation stump had healed. This decision was based on the age and co-morbidities of the patient, and the probability of compliance with a prosthesis.

\section{Statistics}

Statistical analysis of the outcomes of patients discharged from hospital was performed. The associations between the occurrence of wound complications and socioeconomic status factors was determined with the chi-squared (Fisher's exact) test. A p-value of 0.05 or less was considered significant. The same analysis was performed for death in the 1st, 2nd and 3rd year after discharge. Linear associations between these outcomes and socioeconomic factor levels were determined by Spearman's rank correlation test. A Bonferroni adjustment was applied to account for multiple simultaneous tests.

\section{Setting}

The study was conducted at the Steve Biko Academic Hospital which forms part of the medical training platform of the University of Pretoria. The study was conducted between July 2012 and August 2014. Approval for the study was granted by the Research Ethics Committee of the Faculty of Health Sciences of the University of Pretoria (Study number 179/2012). Individual signed consent was obtained from the enrolled patients.

\section{Results}

Ninety-nine patients were enrolled in the study. Patient characteristics are depicted in Table 1 . The average age was 60 years and 7 months. There were more male patients 64 (65\%). Fifty-five percent were current or past smokers. Vascular pathology was peripheral arterial disease (atherosclerosis) (34\%), diabetes mellitus $(63 \%)$ or both (16\%). One patient had HIV-associated vascular disease and two were intravenous drug abusers with inadvertent arterial injury. Fifty-six (57\%) patients were hypertensive. The mean BMI of the whole cohort fell just within the overweight category (25.8) which was the same in patients with diabetes (26.5). Thirteen of the 57 diabetic patients $(23 \%)$ were obese (BMI greater than 30).

Eight patients died during the initial hospitalisation and 91 patients were discharged after a major amputation. All patients were discharged home and none to specialised facilities.

Levels of socioeconomic circumstances to which patients were discharged are depicted in Table 2. Most of the patients were not living in particularly poor circumstances. Brick houses ( 84 patients) and in-house running water (79 patients) predominated. Most patients were living with co-inhabitants (80 patients) and/or had specific people who cared for them at home. While 29 patients were employed or had private

\begin{tabular}{|c|c|c|c|}
\hline Pathology & All (n99) & $\mathrm{DM}(\mathrm{n} 62)^{*}$ & Other $(\mathrm{n} 37) \dagger$ \\
\hline Age (years, range) & $61(24-93)$ & $57(31-81)$ & $64(24-93)$ \\
\hline \multirow[t]{2}{*}{ Gender $(\mathrm{n}, \%)$} & M 64 (65) & M 39 (63) & M $25(68)$ \\
\hline & F $35(35)$ & F 23 (37) & F $12(32)$ \\
\hline \multirow[t]{2}{*}{ Smoker $\ddagger(n, \%)$} & Yes $54(55)$ & Yes $26(42)$ & Yes 27 (73) \\
\hline & No 41 (41) & No 33 (53) & No 8 (22) \\
\hline Hypertension (n.) & 56 & 41 & 15 \\
\hline BMI (mean, range) & $25.8(15-41)$ & $26.5(17-41)$ & $24.18(15-37)$ \\
\hline \multicolumn{4}{|c|}{$\begin{array}{l}* \mathrm{DM}=\text { Diabetes mellitus. Includes } 16 \text { with peripheral arterial } \\
\text { disease (PAD) } \\
\dagger \text { Mostly PAD ( } 34 \text { patients, } 92 \%) \\
\ddagger \text { Current or ex-smoker }\end{array}$} \\
\hline
\end{tabular}


Table 2. Complications and mortality of patients after discharge (n91) by socioeconomic factor levels

\begin{tabular}{|c|c|c|c|c|c|}
\hline $\begin{array}{l}\text { Socioeconomic factor and } \\
\text { level (number of } \\
\text { patients) }\end{array}$ & $\begin{array}{c}\text { Patients with } \\
\text { complications } \\
\mathrm{n}=14^{*}\end{array}$ & $\begin{array}{c}\text { Patients with no } \\
\text { complications } \\
\text { n=71* }\end{array}$ & $\begin{array}{c}\text { Died }<1 \text { year after } \\
\text { Discharge } \\
n=16\end{array}$ & $\begin{array}{l}\text { Died } 1 \text { to } 2 \text { years } \\
\text { after Discharge } \\
\qquad n=7\end{array}$ & $\begin{array}{c}\begin{array}{c}\text { Died }>2 \text { years } \\
\text { after Discharge } \\
n=3\end{array} \\
\end{array}$ \\
\hline \multicolumn{6}{|l|}{ Accommodation, n (\%) } \\
\hline Brick (n84) & $14(100.0)$ & $65(91.5)$ & $15(93.8)$ & $6(85.7)$ & $3(100.0)$ \\
\hline Shack, Other (n4) & 0 & $4(5.6)$ & $1(6.2)$ & 0 & 0 \\
\hline Unknown (n3) & 0 & $2(2.8)$ & 0 & $1(14.3)$ & 0 \\
\hline \multicolumn{6}{|l|}{ Water, n (\%) } \\
\hline Running Water (n79) & $14(100.0)$ & $59(83.0)$ & $11(68.8)$ & $6(85.7)$ & $3(100.0)$ \\
\hline Communal Tap (n4) & 0 & $4(5.6)$ & $2(12.5)$ & 0 & 0 \\
\hline No Access to Water (n5) & 0 & $5(7.0)$ & $3(18.7)$ & 0 & 0 \\
\hline Unknown (n3) & 0 & $3(4.2)$ & 0 & $1(14.3)$ & 0 \\
\hline \multicolumn{6}{|l|}{ Follow-up, n (\%) } \\
\hline Followed up (n74) & $11(78.6)$ & $58(81.7)$ & $13(100.0)$ & $6(85.7)$ & $3(100.0)$ \\
\hline Defaulted (n3) & 0 & $2(2.8)$ & 0 & 0 & 0 \\
\hline Unknown (n14) & $3(21.4)$ & $11(15.5)$ & 0 & $1(14.3)$ & 0 \\
\hline \multicolumn{6}{|l|}{ Cohabitants, n (\%) } \\
\hline Had cohabitants (n80) & $12(85.7)$ & $62(87.3)$ & $16(100.0)$ & $5(71.4)$ & $3(100.0)$ \\
\hline No cohabitants (n8) & $1(7.1)$ & $7(9.6)$ & 0 & $1(14.3)$ & 0 \\
\hline Unknown (n3) & $1(7.1)$ & $2(2.8)$ & 0 & $1(14.3)$ & 0 \\
\hline \multicolumn{6}{|l|}{ Caregiver, n (\%) } \\
\hline Had a caregiver (n81) & $13(92.9)$ & $62(87.3)$ & $16(100.0)$ & $5(71.4)$ & $3(100.0)$ \\
\hline No caregiver (n6) & $1(7.1)$ & $5(7.0)$ & 0 & $1(14.3)$ & 0 \\
\hline Unknown (n4) & 0 & $4(5.6)$ & 0 & $1(14.3)$ & 0 \\
\hline \multicolumn{6}{|l|}{ Income, n (\%) } \\
\hline Salary / private (n29) & $4(28.6)$ & $19(26.8)$ & $2(12.5)$ & $2(28.6)$ & $1(33.3)$ \\
\hline Grant (n49) & $7(50.0)$ & $42(59.1)$ & $11(68.8)$ & $4(57.1)$ & $2(66.7)$ \\
\hline None (n10) & $3(21.4)$ & $7(9.6)$ & $2(12.5)$ & 0 & 0 \\
\hline Unknown (n3) & 0 & $3(4.2)$ & 0 & $1(14.3)$ & 0 \\
\hline \multicolumn{6}{|l|}{ Mobility, n (\%) } \\
\hline $\begin{array}{l}\text { More mobile (crutches, } \\
\text { walking frame) (n28) }\end{array}$ & $5(35.7)$ & $23(32.3)$ & $3(18.8)$ & $3(42.8)$ & 0 \\
\hline $\begin{array}{l}\text { Less Mobile (wheelchair, no } \\
\text { mobility, bedridden) (n40) }\end{array}$ & $7(50.0)$ & $27(38.0)$ & $10(62.5)$ & $2(28.6)$ & $2(66.7)$ \\
\hline Unknown (n23) & $2(14.3)$ & $21(29.6)$ & $3(18.8)$ & $2(28.6)$ & $1(33.3)$ \\
\hline
\end{tabular}

Table 3. Statistical analysis of the incidence of complications and mortality after discharge by level of socioeconomic factors

\begin{tabular}{|c|c|c|c|c|}
\hline & \multicolumn{2}{|c|}{ Complications (n14) } & \multicolumn{2}{|c|}{$\begin{array}{c}\text { Mortality (n26) } \\
\text { Died }<\text { 1yr, 1-2 yrs, > 2yrs }\end{array}$} \\
\hline & p-value* & r-statistic $(p) \dagger$ & p-value* & r-statistic $(p) \dagger$ \\
\hline Accommodation & 1.00 & $-0.11(1.00)$ & 1.00 & $-0.15(1.00)$ \\
\hline Water & 0.20 & $-0.17(1.00)$ & 0.24 & $-0.37(1.00)$ \\
\hline Follow up & 1.00 & $-0.07(1.00)$ & - & - \\
\hline Cohabitants & 0.61 & $0.08(1.00)$ & 0.36 & $0.22(1.00)$ \\
\hline Caregiver & 0.57 & $0.04(1.00)$ & 0.36 & $0.22(1.00)$ \\
\hline Income & 0.62 & $0.04(1.00)$ & 0.79 & $-0.33(1.00$ \\
\hline Mobility & 0.78 & $-0.04(1.00)$ & 0.32 & $-0.13(1.00)$ \\
\hline
\end{tabular}


incomes, more than half were dependant on state/government grants. The latter consisted mainly of old age pensions. Most patients were aware of a reasonably accessible medical facility to which they could go for treatment.

Compliance with follow-up was good. Of the 91 patients who were discharged from hospital, 74 (81\%) attended follow-up regularly at the hospital or local clinics until healing of their wounds was deemed to be satisfactory. Mobility of patients was in general deficient: one third managed on crutches or a walking frame, but the rest were dependant on helpers, being either in a wheelchair, immobile or bedridden. Only seven patients were supplied with limb prostheses in the follow-up period.

The socioeconomic circumstances of patients who developed complications or died after discharge are also shown in Table 2. Eighty-five patients were discharged from hospital with healed wounds. Local complications developed in 14 patients $(16 \%)$ after discharge. These consisted of wound sepsis or non-healing. Twenty-six patients died in the follow-up period: 16 in the first year, 7 in the second year and 3 in the third year.

Table 3 shows the analysis of the association of the level of socioeconomic factors of the patients with mortality and wound complications after discharge from hospital. While there was a trend towards association of the lack of running water and both mortality and wound complications, none of the factors were statistically significant on Fisher's exact test. The Spearman's rank correlation test revealed the same result with low r-values and p-values of 1 in all calculations.

\section{Discussion}

We present a study of the influence of socioeconomic factors on the outcome of dysvascular amputees. A study of this nature has apparently not been published previously. This study was performed in an urban South African setting. We had hypothesised that morbidity and mortality of our patients post major lower extremity amputation would be significantly higher because of less than ideal circumstances and social deprivation. This proved not to be the case. Measures such as the standard of housing and income surprisingly indicated a degree of relative affluence.

The Steve Biko Academic Hospital serves the city of Pretoria and surroundings as well as a large mostly rural province. The hospital is a public sector institution serving mainly uninsured and low income patients, although it is accessible to all inner city residents. The large South African cities are surrounded by vast peri-urban townships populated by mainly African people. These townships consist mainly of basic brick houses which either have household running water or are served by communal taps. Interspersed in between are great numbers of informal settlements and squatter camps of houses constructed of found and scavenged materials. These informal settlements are areas of severe social deprivation.

Measures of socioeconomic status that are used for epidemiological studies have been formulated in the developed world. ${ }^{11,12}$ They are complex and may not be applicable to Africa for which few indicators have been developed. Barbarin and Khomo have proposed a social and economic status indicator for residents of South African townships. ${ }^{13}$ This is complex and meant for sociological studies of child health, although it does also encompass the standard of housing. It does not include monetary indicators and was not considered to be suitable for our study. We evaluated housing, cohabitation and income as basic indicators of the ability to care for a patient with a fresh amputation stump and the ability to access health care facilities. We could not demonstrate deficiency of these basic factors nor a statistically significant effect of them on outcome in our cohort of amputation patients.

No comprehensive studies of the effect of socioeconomic factors on post-discharge outcome of amputees have been published. Some studies touch on this aspect. A lower level of education, ${ }^{14}$ discharge of patients without co-habitants ${ }^{15}$ and discharge to non-home supportive facilities ${ }^{16}$ have been shown to result in worse outcomes. Published studies do not report systematically on socioeconomic circumstances after discharge. Our study is the first to attempt to evaluate the effect of post-hospitalisation factors on the outcome of amputees in a prospective study.

Early mortality after major amputation has been shown to be significant, both in hospital and after discharge, ${ }^{2,3}$ and 1-year mortality of up to $54 \%$ has been reported. ${ }^{17}$ The 3 -year mortality in the current series was $32 \%$. This was not apparently related to the circumstances to which patients were discharged. The major determinants of mortality were medical comorbidities.

Care of leg amputees has been reported to be less than optimal in the developed world. ${ }^{17}$ Care in the developing world would be expected to be sub-optimum following major lower extremity amputations. Reports from Africa dwell on peri-operative events and the lack of rehabilitation, as well as a different predominantly non-vascular aetiological spectrum, but do not address post-discharge circumstances. ${ }^{19,20}$

Health and disease are inextricably related to social determinants. ${ }^{21}$ We evaluated basic socioeconomic indicators after hospitalisation on the premise that most of our patients would be severely socio-economically challenged. However, the vast majority of the patients in our study lived in brick houses with running water and had some form of income. This is probably the reason why we could not demonstrate a significant adverse effect of socioeconomic factors on conventional outcomes in dysvascular amputees. A study of amputation for trauma and malignancy may show an effect of such factors on outcome because of the probable paucity of diabetic or vascular disease comorbidities in a less affluent population. The patients with vascular pathology studied here, who were nevertheless from the generally less privileged strata of our population, did not show such an effect. Diabetes mellitus and atherosclerosis may be indicators of relative affluence in our society. 


\section{Conclusion}

This prospective clinical study focusses on the effect of the level of socio-economic circumstances on the outcome of dysvascular amputees from a developing world setting. None of the measures of post-discharge social or economic factors were statistically associated with mortality or wound morbidity in a cohort of major lower extremity amputees. This study demonstrated relatively favourable living conditions and socioeconomic status of the study patients, highlighting the association of such conditions with diabetes mellitus and vascular disease. A study of amputation for indications other than arterial disease and diabetes could possibly show an impact of socioeconomic circumstances on outcome.

The authors have no conflicts of interest to declare.

\section{Acknowledgements}

\section{None}

\section{Conflicts of interest}

None

\section{Author contributions}

VOLK: Concept, study design, literature research, principal writer, final approval.

PBM: Literature review, collection of data, writing of report, final approval.

TM: Study design, critical review of report, final approval.

\section{Funding}

This research did not receive any specific funding.

\section{REFERENCES}

1. Kulkarni J, Pande S, Morris J. Survival rates in dysvascular lower limb amputees. Int J Surg. 2006;4:217-21.

2. Papazafiropoulou A, Tentolouris N, Soldatos RP, Liapis CD, Dounis E, et al. Mortality in diabetic and nondiabetic patients after amputations performed from 1996 to 2005 in a tertiary hospital population: a 3-year follow-up study. J Diabetes Complications. 2009;23(1):7-11.

3. Easterlin MC, Chang DC, Wilson SE. A practical index to predict 30-day mortality after major amputation. Ann Vasc Surg. 2013;27(7):909-17.

4. Curran T, Zhang JQ, Lo RC, Fokkema M, McCallum JC, et al. Risk Factors and Indications for Readmission Following Lower Extremity Amputation in the ACS-NSQIP. J Vasc Surg. 2014;60(5):1315-24.

5. Scott SW, Bowrey S, Clarke D, Choke E, Bown MJ, et al. Factors influencing short- and long-term mortality after lower limb amputation. Anaesthesia. 2014;69:249-58.
6. Fortington LV, Geertzen JHB, van Netten JJ, Postema K, Rommers GM. Short and long term mortality rates after a lower limb amputation. Eur J Vasc Endovasc Surg. 2013;46(1):124-31.

7. Dillingham TR, Pezzin LE. Rehabilitation setting and associated mortality and medical stability among persons with amputations. Arch Phys Med Rehabil. 2008;89(6):1038-45.

8. Sauter CN, Pezzin LE, Dillingham TR. Functional outcomes of persons who underwent dysvascular lower extremity amputations: effect of postacute rehabilitation setting. Am J Phys Med Rehabil. 2013;92(4):287-96.

9. Hakkarainen TW, Arbabi S, Willis MM, Davidson GH, Flum DR. Outcomes of patients discharged to skilled nursing facilities after acute care hospitalizations. Ann Surg. 2016;263(2):280-5.

10. Harris AR, Bowley DM, Stannard A, Kurrimboccus S, Geh JI, et al. Socioeconomic deprivation adversely affects survival of patients with rectal cancer. B J Surg. 2009;96(7):763-8.

11. Galobardes B, Shaw M, Lawlor DA, Lynch JW, Davey Smith G. Indicators of socioeconomic position (part 1). J Epidemiol Community Health. 2006;60:7-12.

12. Galobardes B, Shaw M, Lawlor DA, Lynch JW, Davey Smith G. Indicators of socioeconomic position (part 2). J Epidemiol Community Health. 2006;60:95-101.

13. Barbarin OA, Khomo N. Indicators of economic status and social capital in South African townships. Childhood. 2016;4(2):193-222.

14. Corey MR, St Julien J, Miller C, Fisher B, Cederstrand SL, et al. Patient education level affects functionality and long term mortality after major lower extremity amputation. Am J Surg. 2012;204(5):626-30.

15. Engelbert TL, Fernandes-Taylor S, Gupta PK, Kent KC, Matsumura J. Clinical characteristics associated with readmission among patients undergoing vascular surgery. J Vasc Surg. 2014;59(5):1349-55.

16. Kayssi A, de Mestral C, Forbes TL, Roche-Nagle G. Predictors of hospital readmissions after lower extremity amputations in Canada. J Vasc Surg. 2016;63(3):688-95.

17. Patterson AJ, Degnan AJ, Walsh SR, Eltayeb M, Scout EF, et al. Efficacy of VBHOM to predict outcome following major lower limb amputation. Vasc Endo Surg. 2012;46(5):369-73.

18. National Confidential Enquiry into Patient Outcome and Death. [Internet] Lower limb amputation: working together. NCEPOD; [updated 2014; cited 6 Jun 2017]. Available from: http://www. ncepod.org.uk/2014report2/downloads/WorkingTogetherFull Repo rt.pdf

19. Yinusa W, Ugbeye ME. Problems of amputation surgery in a developing country. Int Orthop. 2003;27:121-4.

20. Chalya PL, Mabula JB, Dass RM, Ngayomela IH, Chandika $\mathrm{AB}$, et al. Major limb amputations: a tertiary hospital experience in North-western Tanzania. J Orthop Surg Res. 2012;7:18.

21. Marmot M. Social determinants of health inequalities. Lancet. 2005;365:1099-104. 